\title{
Intrasession repeatability of ocular anatomical measurements obtained with a multidiagnostic device in healthy eyes
}

\author{
David P. Piñero ${ }^{1 *}$, Inmaculada Cabezos ${ }^{1}$, Alberto López-Navarro², Dolores de Fez', María T. Caballero \\ and Vicente J. Camps ${ }^{1}$
}

\begin{abstract}
Background: To evaluate the intrasession repeatability of anterior chamber depth (ACD), central (CCT) and peripheral corneal thickness (PCT), white-to-white diameter (WTW), and irido-corneal angle (IA) measurements obtained with a multidiagnostic device in healthy eyes.
\end{abstract}

Methods: A total of 107 eyes of 107 patients ranging in age from 23 to 65 years were examined with the VX120 system (Visionix-Luneau Technologies). Three consecutive measurements were obtained with this device to assess the intrasession repeatability of ACD, CCT, PCT at different nasal and temporal locations, WTW, and nasal and temporal IA. Data analysis included the calculation of within-subject standard deviation $\left(\mathrm{S}_{\mathrm{w}}\right)$, intrasubject precision $\left(1.96 \times S_{w}\right)$, coefficient of variation (CV) and intraclass correlation coefficient (ICC).

Results: The $S_{w}$ and $C V$ for $A C D$ was $0.03 \mathrm{~mm}$ and $1.16 \%$, respectively, with an ICC of 0.992 . The $S_{w}$ values for central and peripheral pachymetric measurements were below $9 \mu \mathrm{m}$, with CV of less than $1.6 \%$ and ICC of 0.976 or higher. For IA measurements, $S_{w}$ values of 0.84 or lower were found, with a CV between 1 and 2\%, and an ICC of more than 0.970 . The $S_{w}$ for WTW was $0.24 \mathrm{~mm}$ and the CV was $1.95 \%$. No statistically significant correlations were found between any anatomical parameter evaluated and their $S_{w}$ and $C V$ values associated $(-0.220 \leq r \leq 0.204, p \geq 0.125)$.

Conclusions: The VX120 system is able to provide repeatable measurements of anatomical parameters in healthy eyes. Inter-observer repeatability should be evaluated in future studies.

Keywords: Anterior chamber depth, Pachymetry, White-to-white, Irido-corneal angle, Scheimpflug imaging, VX120 system

\section{Background}

Accurate measurement of different anatomical dimensions of the anterior segment is crucial in the eye care clinical practice [1]. These accurate measurements allow the clinician to perform a precise planning of refractive and intraocular surgical procedures, to check the viability of a specific type of surgical technique, and to perform comprehensive monitoring of ocular diseases. Thus, clinical decisions based on unreliable or not consistent data are avoided. There are several studies evaluating the repeatability of anterior segment anatomical

\footnotetext{
* Correspondence: david.pinyero@ua.es

${ }^{1}$ Group of Optics and Visual Perception, Department of Optics, Pharmacology and Anatomy, University of Alicante, Crta San Vicente del Raspeig s/n 03016, San Vicente del Raspeig, Alicante, Spain

Full list of author information is available at the end of the article
}

measurements provided by different types of instruments, most of them based on Scheimpflug imaging or partial coherence interferometry [2-19]. Specifically, good intrasession repeatability data have been reported with a variety of devices for anterior chamber depth (ACD), [2-19] central corneal thickness (CCT), [4, 6, 10, 13-18] peripheral corneal thickness (PCT) [21], whiteto-white corneal diameter, $[3,5,8-10,14,15,20]$ and irido-corneal angle (IA) $[6,10,19,21]$. All these studies confirm the good performance of currently available devices for measuring the anatomical dimensions of the anterior segment of the eye.

Recently, a new multidiagnostic platform has been developed that provides automatic measurements of corneal topography, corneal, internal and ocular aberrations, pachymetry, anterior chamber depth, irido-corneal 
angle, pupil diameter under different luminance conditions and intraocular pressure (IOP), which is the VX120 system (Visionix-Luneau Technologies, Chartres, France). To date, there are no scientific studies evaluating the reliability of this device. The aim of the current study was to evaluate the intrasession repeatability of anterior segment anatomical measurements obtained with the VX120 system in a sample of normal healthy eyes.

\section{Methods}

\section{Patients}

A total of 107 healthy eyes of 107 patients ranging in age from 23 to 65 years old were enrolled in this prospective study of evaluation of a technology. All subjects were selected randomly from patients attending to the Optometry Clinic of the University of Alicante, where this investigation was developed. One eye only from each subject was chosen randomly for the study using a random number sequence (dichotomic sequence, 0 and 1 ) in order to avoid the potential interference of the correlation that often exists between the two eyes of the same person. All patients were informed previously about the study and signed an informed consent in accordance with the tenets of the Helsinki Declaration. An approval for the performance of the study was obtained from the Ethics Committee of the University of Alicante (Spain).

The inclusion criteria were the following: eyes without active ocular pathology, age of more than 18 years, and the presence of a refractive error between +5.00 and $-10.00 \mathrm{D}$. The following conditions were defined as exclusion criteria for the study: any systemic pathology at the moment of examination, previous ocular surgery, glaucoma, less than 18 complete consecutive Placido rings projected on the cornea and therefore considered for the corneal analysis, pseudophakia, corneal ectatic diseases, and any other type of pathological condition of the eye.

\section{Examination protocol}

A complete eye exam was performed in all cases that included measurement of uncorrected (UDVA) and corrected distance visual acuity (CDVA), manifest refraction, air tonometry (VX120 system, VisionixLuneau Technologies, Chartres, France), and corneal topographic and anterior segment analysis with the VX120 system (Visionix-Luneau Technologies, Chartres, France). All measurements were performed by the same experienced examiner (ALN), taking three consecutive measurements in order to analyze the intrasession repeatability of some anatomical measurements. Specifically, the repeatability of the following parameters was evaluated: anterior chamber depth (ACD), peripheral corneal thickness at 1,2 and $3 \mathrm{~mm}$ from vertex nasally $\left(\mathrm{PCT}_{\mathrm{N} 1}, \mathrm{PCT}_{\mathrm{N} 2}\right.$, and $\left.\mathrm{PCT}_{\mathrm{N} 3}\right)$, peripheral corneal thickness at 1,2 and $3 \mathrm{~mm}$ from vertex temporally $\left(\mathrm{PCT}_{\mathrm{T} 1}, \mathrm{PCT}_{\mathrm{T} 2}\right.$, and $\left.\mathrm{PCT}_{\mathrm{T} 3}\right)$, central corneal thickness (CCT) (Fig. 1), nasal and temporal irido-corneal angles $\left(\mathrm{IA}_{\mathrm{N}}\right.$ and $\left.\mathrm{IA}_{\mathrm{T}}\right)$, and horizontal white-to-white corneal diameter (WTW).

\section{The VX120 system}

The VX120 system is a multidiagnostic platform that combines several technologies in order to provide an integral exam of the anterior segment of the eye. Specifically, the system combines a Scheimpflug imaging-based system, a Placido disk corneal topographer, a Hartmann-Shack aberrometer, and an air tonometer. The information used to provide all corneal topographic information is provided by a Placido disk system that projects 24 rings on the corneal surface, measuring more than 100,000 points. Refractive and ocular aberrometric data are obtained with a Hartmann-Shack system that measures 1500 points in $0.2 \mathrm{~s}$ in an area ranging from 2.0 to $7.0 \mathrm{~mm}$ of diameter.

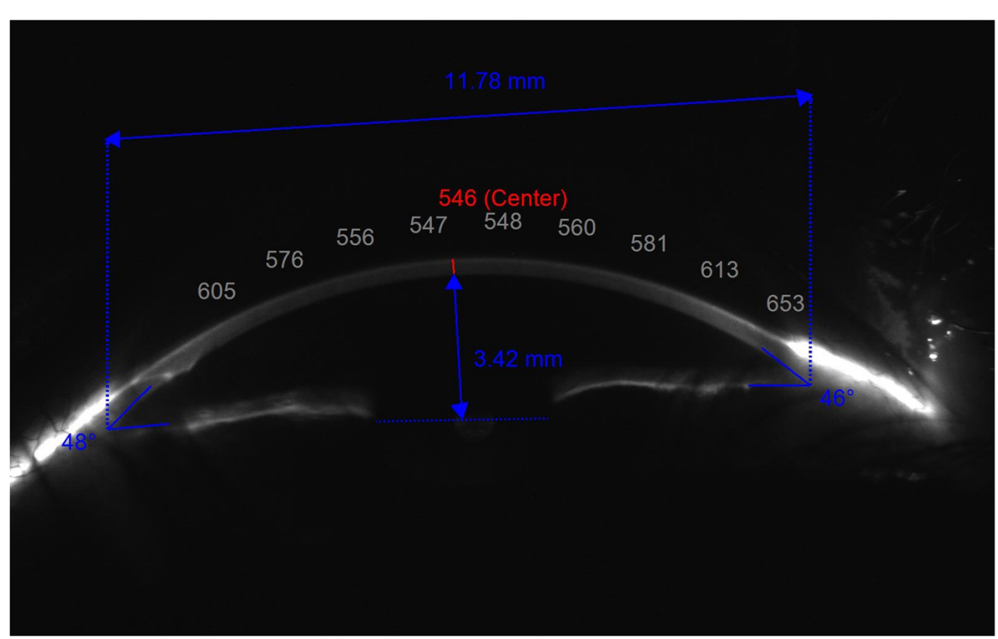

Fig. 1 Horizontal scan obtained with the Scheimpflug camera of the VX120 system in which peripheral pachymetric measurements are done 
The Scheimpflug imaging-based system uses monochromatic blue light of $455 \mathrm{~nm}$ to obtain pachymetric measurements with a resolution of $\pm 1 \mu \mathrm{m}$, and iridocorneal angle measurements with a resolution of $\pm 1^{\circ}$. With the data obtained with all these technologies, the system also provides tangential and axial curvature data of the anterior corneal surface, internal wavefront aberrations, visual quality simulations, central and peripheral corneal pachymetry data, and IOP measurements.

\section{Statistical analysis}

The statistical analysis was performed using the software SPSS version 15.0 for Windows (SPSS, Chicago, Illinois, USA). Normality of all data distributions was confirmed by means of the Kolmogorov-Smirnov test. Then, parametric statistics was applied. Intrasession repeatability for anatomical parameters was assessed according to the following variables: the within-subject standard deviation $\left(\mathrm{S}_{\mathrm{w}}\right)$ of the 3 consecutive measurements, intrasubject precision $\left(1.96 \times \mathrm{S}_{\mathrm{w}}\right)$, and the intraclass correlation coefficient (ICC). The within-subject standard deviation $\left(\mathrm{S}_{\mathrm{w}}\right)$ is a simple way of estimating the size of the measurement error. The intraobserver precision was defined as $\left( \pm 1.96 \times \mathrm{S}_{\mathrm{w}}\right)$ and this parameter indicates how large is the range of error of the repeated measurements for $95 \%$ of observations. Finally, the ICC is an ANOVA-based type of correlation that measures the relative homogeneity within groups (between the repeated measurements) in ratio to the total variation. The ICC will approach 1.0 when there is no variance within repeated measurements, indicating total variation in measurements is due solely to variability in the parameter being measured. Furthermore, Pearson correlation coefficients were used to assess the correlation between different parameters evaluated. All statistical tests were 2-tailed, and $p$-values less than 0.05 were considered statistically significant.

\section{Results}

Table 1 summarizes the main characteristics of the sample evaluated. The sample was comprised of 49 males (45.8\%) and 58 females (54.2\%), with a mean age of 47.8 years old. Table 2 summarizes the outcomes of the intrasession repeatability analysis for all anatomical parameters evaluated. The $S_{w}$ and $C V$ for $A C D$ was $0.03 \mathrm{~mm}$ and $1.16 \%$, respectively, with an ICC 0.992 . The $S_{w}$ values for central and peripheral pachymetric measurements were below $9 \mu \mathrm{m}$, with $\mathrm{CV}$ of less than $1.6 \%$ and ICC of 0.976 or higher. For IA measurements, $\mathrm{S}_{\mathrm{w}}$ values of 0.84 or lower were found, with a CV between 1 and $2 \%$, and ICC of more than 0.970 . The $S_{w}$ for WTW was $0.24 \mathrm{~mm}$ and the CV was $1.95 \%$.

Table 3 displays the coefficients of correlation of the magnitude of different anatomical parameters and the $S_{w}$ and $\mathrm{CV}$ values associated to each parameter. As shown,
Table 1 Main characteristics of the sample evaluated

\begin{tabular}{llll}
\hline & Mean (SD) & Median & Range \\
\hline Age (years) & $47.8(8.3)$ & 47.0 & 23.0 to 65.0 \\
$\begin{array}{l}\text { Mean central corneal } \\
\text { radius (mm) }\end{array}$ & $7.92(0.30)$ & 7.86 & 7.26 to 8.84 \\
$\begin{array}{l}\text { Mean central corneal } \\
\text { astigmatism (D) }\end{array}$ & $0.82(0.59)$ & 0.75 & 0.00 to 3.75 \\
$\begin{array}{l}\text { Manifest sphere (D) } \\
\text { Manifest cylinder (D) }\end{array}$ & $-0.43(2.02)$ & 0.00 & -7.00 to 6.00 \\
$\begin{array}{l}\text { Manifest spherical } \\
\text { equivalent (D) }\end{array}$ & $-0.63(2.03)$ & 0.00 & -4.00 to 0.00 \\
Corneal eccentricity & $0.34(0.31)$ & 0.43 & -7.33 to 5.50 \\
\hline
\end{tabular}

Abbreviations: $S D$ standard deviation, $D$ diopter

no statistically significant correlations were found $(-0.220 \leq r \leq 0.204, p \geq 0.125)$. Likewise, no significant correlations were found between mean keratometry, corneal eccentricity, corneal astigmatism or spherical equivalent and the $S_{\mathrm{w}}$ values obtained for each anatomical parameter evaluated $(-0.253 \leq r \leq 0.275, p \geq 0.125)$.

\section{Discussion}

The concept of integrating several clinical tests in one device in order to simplify the activity in clinical setting has been investigated extensively in the last years. Some multidiagnostic platforms combining different technologies have been developed and commercially released [1, 21-23]. One of the potential concerns about these systems if they are able to provide consistent and reliable measurements that can be considered as interchangeable with those measurements provided by goldstandard or widely tested devices. The current study was aimed at confirming if one experienced operator was able to obtain repeatable measurements of different anatomical parameters of the anterior segment with the multidiagnostic platform VX120. If this intrasession repeatability is confirmed, future studies will be conducted to analyze the inter-observer repeatability and the interchangeability of VX120 measurements with those obtained by other different currently available topography systems or tomographers.

In our study, the intrasession repeatability of $\mathrm{ACD}$ measurements was excellent, with $S_{w}$ of $0.03 \mathrm{~mm}, \mathrm{CV}$ of $1.16 \%$ and ICC of 0.992 . This confirms that the multidiagnostic device evaluated is able to provide repeatable consecutive measurements of the depth of the anterior chamber of the healthy eye. Our intrasession repeatability outcomes for ACD are consistent with those reported with other commercially available devices, including Scheimpflug-based topography systems, [3, 5, 6, 10-14, 16-19] biometers, [2-4, 8, 9, 15, 17] and optical coherence tomographers [3, 11] (Table 4). Kurian et al. [2] obtained in 100 eyes evaluated with the 
Table 2 Summary of the intrasession repeatability outcomes for the anatomical measurements evaluated with the VX120 system

\begin{tabular}{|c|c|c|c|c|c|}
\hline & Overall mean (SD) Overall median (Range) & $\mathrm{S}_{\mathrm{w}}$ & $\operatorname{Pr}$ & CV (\%) & ICC (Range 95\% Cl) \\
\hline$\overline{A C D}(\mathrm{~mm})$ & $\begin{array}{l}2.86(0.29) \\
2.83(2.10 \text { to } 3.77)\end{array}$ & 0.03 & 0.06 & 1.16 & $\begin{array}{l}0.992 \\
\text { (0.989 to } 0.994)\end{array}$ \\
\hline $\mathrm{PCT}_{\mathrm{N} 3}(\mu \mathrm{m})$ & $\begin{array}{l}592.04(39.87) \\
601.00 \text { (533.67 to } 699.00)\end{array}$ & 8.98 & 17.59 & 1.52 & $\begin{array}{l}0.976 \\
(0.957 \text { to } 0.987)\end{array}$ \\
\hline $\mathrm{PCT}_{\mathrm{N} 2}(\mu \mathrm{m})$ & $\begin{array}{l}567.77(37.83) \\
575.67(506.33 \text { to } 675.33)\end{array}$ & 7.05 & 13.81 & 1.25 & $\begin{array}{l}0.984 \\
\text { (0.971 to } 0.991)\end{array}$ \\
\hline $\mathrm{PCT}_{\mathrm{N} 1}(\mu \mathrm{m})$ & $\begin{array}{l}574.89(45.35) \\
549.67(508.33 \text { to } 699.00)\end{array}$ & 7.70 & 15.09 & 1.34 & $\begin{array}{l}0.984 \\
\text { (0.972 to } 0.992)\end{array}$ \\
\hline $\mathrm{CCT}(\mu \mathrm{m})$ & $\begin{array}{l}545.88(34.70) \\
544.67(428.00 \text { to } 657.67)\end{array}$ & 6.41 & 12.56 & 1.17 & $\begin{array}{l}0.983 \\
(0.977 \text { to } 0.988)\end{array}$ \\
\hline $\mathrm{PCT}_{\mathrm{T} 1}(\mu \mathrm{m})$ & $\begin{array}{l}553.27(37.44) \\
545.67(492.00 \text { to } 664.33)\end{array}$ & 5.91 & 11.59 & 1.08 & $\begin{array}{l}0.987 \\
\text { (0.977 to } 0.993)\end{array}$ \\
\hline $\mathrm{PCT}_{\mathrm{T} 2}(\mu \mathrm{m})$ & $\begin{array}{l}568.70(37.58) \\
573.33 \text { (510.67 to } 681.33)\end{array}$ & 6.06 & 11.87 & 1.07 & $\begin{array}{l}0.987 \\
(0.977 \text { to } 0.993)\end{array}$ \\
\hline $\mathrm{PCT}_{\mathrm{T} 3}(\mu \mathrm{m})$ & $\begin{array}{l}593.76(38.58) \\
598.67(529.00 \text { to } 708.00)\end{array}$ & 8.33 & 16.33 & 1.41 & $\begin{array}{l}0.979 \\
(0.963 \text { to } 0.989)\end{array}$ \\
\hline $\mid A_{N}\left({ }^{\circ}\right)$ & $\begin{array}{l}37.17(4.35) \\
37.00(28.33 \text { to } 46.00)\end{array}$ & 0.84 & 1.65 & 2.23 & $\begin{array}{l}0.970 \\
\text { (0.946 to } 0.984)\end{array}$ \\
\hline $\mid A_{T}\left({ }^{\circ}\right)$ & $\begin{array}{l}39.63(4.59) \\
39.67 \text { (30.67 to } 50.33)\end{array}$ & 0.52 & 1.02 & 1.32 & $\begin{array}{l}0.994 \\
(0.988 \text { to } 0.997)\end{array}$ \\
\hline WTW (mm) & $\begin{array}{l}12.21(0.57) \\
12.17(10.99 \text { to } 13.94)\end{array}$ & 0.24 & 0.46 & 1.95 & $\begin{array}{l}0.873 \\
(0.823 \text { to } 0.911)\end{array}$ \\
\hline
\end{tabular}

Abbreviations: $S D$ standard deviation, $C V$ coefficient of variation, $S_{w}$ within-subject standard deviation, $P r$ intrasubject precision: $1.96 \times S_{w}, I C C$ intraclass correlation coefficient, $A C D$ anterior chamber depth, $P C T_{N 1}, P C T_{N 2}$, and $P C T_{N 3}$ peripheral corneal thickness at 1, 2 and 3 mm from vertex nasally, $P C T_{T 1}, P C T_{T 2}$, and $P C T_{T 3}$ peripheral corneal thickness at 1, 2 and $3 \mathrm{~mm}$ from vertex temporally, $C C T$ central corneal thickness, $I A_{N}$ and $I A_{T}$ nasal and temporal irido-corneal angles and WTW horizontal white-to-white corneal diameter

IOL-Master (Carl Zeiss Meditec) and Lenstar 900 (Haag-Streit) optical biometry systems, $S_{w}$ values for $\mathrm{ACD}$ of 0.04 and $0.06 \mathrm{~mm}$, and $\mathrm{CV}$ of 1.22 and $1.99 \%$, respectively. Kunert and coauthors [4] found a $\mathrm{S}_{\mathrm{w}}$ value for ACD of $0.0098 \mathrm{~mm}$ with the optical biometry system IOL Master 700 (Carl Zeiss Meditec).
Other authors have also reported $S_{w}$ values below $0.06 \mathrm{~mm}$ for the same and other optical biometers $[8,9,15,17]$. Likewise, several studies have evaluated the consistency of ACD measurements using Scheimpflug imaging-based topography systems, such as the Sirius (CSO), Galilei (Ziemer) and Pentacam

Table 3 Summary of correlations between the different anatomical parameters and their within-subject standard deviation $\left(\mathrm{S}_{\mathrm{w},}\right)$ and coefficient of variation (CV) associated

\begin{tabular}{|c|c|c|c|c|}
\hline & \multicolumn{2}{|l|}{$\mathrm{S}_{\mathrm{w}}$} & \multicolumn{2}{|l|}{$\mathrm{CV}$} \\
\hline & Pearson correlation coefficient & $p$-value & Pearson correlation coefficient & $p$-value \\
\hline $\mathrm{ACD}(\mathrm{mm})$ & 0.033 & 0.734 & -0.058 & 0.550 \\
\hline $\mathrm{PCT}_{\mathrm{N} 3}(\mu \mathrm{m})$ & 0.024 & 0.893 & -0.082 & 0.652 \\
\hline $\mathrm{PCT}_{\mathrm{N} 2}(\mu \mathrm{m})$ & -0.125 & 0.487 & -0.220 & 0.218 \\
\hline $\mathrm{PCT}_{\mathrm{N} 1}(\mu \mathrm{m})$ & 0.101 & 0.577 & 0.000 & 0.999 \\
\hline $\mathrm{CCT}(\mu \mathrm{m})$ & 0.149 & 0.127 & 0.056 & 0.565 \\
\hline $\mathrm{PCT}_{\mathrm{T} 1}(\mu \mathrm{m})$ & -0.069 & 0.704 & -0.158 & 0.381 \\
\hline $\mathrm{PCT}_{\mathrm{T} 2}(\mu \mathrm{m})$ & -0.059 & 0.746 & -0.142 & 0.431 \\
\hline $\mathrm{PCT}_{\mathrm{T} 3}(\mu \mathrm{m})$ & 0.000 & 0.997 & -0.100 & 0.580 \\
\hline $\mid A_{N}\left({ }^{\circ}\right)$ & 0.204 & 0.254 & 0.122 & 0.498 \\
\hline $\mid A_{T}\left(^{\circ}\right)$ & 0.039 & 0.827 & -0.102 & 0.572 \\
\hline WTW (mm) & -0.109 & 0.282 & -0.154 & 0.125 \\
\hline
\end{tabular}

Abbreviations: $S D$ standard deviation, $C V$ coefficient of variation, $S_{w}$ within-subject standard deviation, $\operatorname{Pr}$ intrasubject precision: $1.96 \times S_{w}, I C C$ intraclass correlation coefficient, $A C D$ anterior chamber depth, $P C T_{N 1}, P C T_{N 2}$, and $P C T_{N 3}$ peripheral corneal thickness at 1,2 and $3 \mathrm{~mm}$ from vertex nasally, $P C T_{T 1}, P C T_{T 2}$, and $P C T_{T 3}$ peripheral corneal thickness at 1,2 and $3 \mathrm{~mm}$ from vertex temporally, $C C T$ central corneal thickness, $I A_{N}$ and $I A_{T}$ nasal and temporal irido-corneal angles, and WTW horizontal white-to-white corneal diameter 
Table 4 Summary of the results of previous studies evaluating the consistency of anterior chamber depth (ACD), peripheral corneal thickness (PCT), central corneal thickness (CCT), iridocorneal angle (IA), and white-to-white corneal diameter (WTW)

\begin{tabular}{|c|c|c|c|c|c|c|c|c|c|}
\hline Authors & Year & Number of eyes & Type of eyes & System & Parameter & $1.96 \mathrm{Sw}$ & Sw & ICC & $\mathrm{CoV}$ \\
\hline Kurian et al. [2] & 2016 & 100 & Healthy & $\begin{array}{l}\text { IOL Master } 700 \\
\text { Lenstar } 900\end{array}$ & $A C D$ & - & $\begin{array}{l}0.04 \mathrm{~mm} \\
0.06 \mathrm{~mm}\end{array}$ & - & $\begin{array}{l}1.22 \% \\
1.99 \%\end{array}$ \\
\hline Shajari et al. [3] & 2016 & 40 & Healthy & $\begin{array}{l}\text { Pentacam HR } \\
\text { IOL Master } 500 \\
\text { Lenstar } 900 \\
\text { Visante OCT } \\
\text { Pentacam HR } \\
\text { IOL Master } 500 \\
\text { Lenstar } 900 \\
\text { Visante OCT }\end{array}$ & $\begin{array}{l}\text { WTW } \\
\text { ACD }\end{array}$ & $\begin{array}{l}0.5 \\
0.5 \\
0.5 \\
0.6 \\
0.3 \\
0.3 \\
0.3 \\
0.3\end{array}$ & - & - & - \\
\hline Shin et al. [5] & 2016 & 140 & Cataract & Galilei G6 & $\begin{array}{l}\text { WTW } \\
\text { ACD }\end{array}$ & - & - & $>0.980$ & - \\
\hline Kunert et al. [4] & 2016 & 120 & Cataract & IOL Master 700 & $\begin{array}{l}C C T \\
A C D\end{array}$ & - & $\begin{array}{l}19.5 \mu \mathrm{m} \\
9.8 \mu \mathrm{m}\end{array}$ & - & - \\
\hline Prakash et al. [6] & 2016 & 100 & Healthy & Sirius & $\begin{array}{l}C C T \\
A C D \\
\text { IA }\end{array}$ & $\begin{array}{l}5 \mu \mathrm{m} \\
0.06 \mathrm{~mm} \\
<2^{\circ}\end{array}$ & - & - & - \\
\hline Huang et al. [8] & 2015 & $\begin{array}{l}52 \\
46\end{array}$ & $\begin{array}{l}\text { Healthy } \\
\text { Cataract }\end{array}$ & Aladdin & $\begin{array}{l}\text { WTW } \\
\text { ACD }\end{array}$ & - & $0.80 \mathrm{~mm}$ & $\begin{array}{l}>0.94 \\
0.795\end{array}$ & $<0.89 \%$ \\
\hline $\begin{array}{l}\text { Srivannaboon } \\
\text { et al. [9] }\end{array}$ & 2015 & 100 & Cataract & IOL Master 500/700 & $\begin{array}{l}\text { WTW } \\
\text { ACD }\end{array}$ & - & - & 0.93 to 1.00 & - \\
\hline Masoud et al. [10] & 2015 & 100 & Healthy & Sirius & $\begin{array}{l}\mathrm{IA} \\
\mathrm{ACD}\end{array}$ & - & - & - & $<2 \%$ \\
\hline Wang et al. [11] & 2015 & 71 & Healthy & $\begin{array}{l}\text { Galilei G2 } \\
\text { Visante OCT } \\
\text { Sirius } \\
\text { Pentacam }\end{array}$ & $A C D$ & - & 0.04 to $0.07 \mathrm{~mm}$ & - & - \\
\hline Shetty et al. [13] & 2014 & 55 & Keratoconus & $\begin{array}{l}\text { Pentacam } \\
\text { Galilei } \\
\text { Sirius }\end{array}$ & $A C D$ & - & $\begin{array}{l}0.03 \mathrm{~mm} \\
0.05 \mathrm{~mm} \\
0.03 \mathrm{~mm}\end{array}$ & - & $\begin{array}{l}1.1 \% \\
1.3 \% \\
1.0 \%\end{array}$ \\
\hline $\begin{array}{l}\text { Hernández-Camarena } \\
\text { et al. [12] }\end{array}$ & 2014 & 84 & Healthy & $\begin{array}{l}\text { Galilei G2 } \\
\text { Pentacam HR } \\
\text { Sirius }\end{array}$ & $\begin{array}{l}C C T \\
A C D\end{array}$ & - & - & - & $<1 \%$ \\
\hline Zhao et al. [15] & 2013 & 56 & Healthy & Lenstar 900 & $\begin{array}{l}\text { WTW } \\
\text { ACD } \\
\text { CCT }\end{array}$ & - & $\begin{array}{l}0.274 \mathrm{~mm} \\
0.052 \mathrm{~mm} \\
14.24 \mu \mathrm{m}\end{array}$ & - & - \\
\hline $\begin{array}{l}\text { Montalban } \\
\text { et al. [14] }\end{array}$ & 2013 & 61 & Keratoconus & Sirius & $\begin{array}{l}\text { WTW } \\
\text { CCT } \\
\text { ACD }\end{array}$ & - & $\begin{array}{l}0.07 \mathrm{~mm} \\
2.30 \mu \mathrm{m} \\
0.02 \mathrm{~mm}\end{array}$ & $\begin{array}{l}0.989 \\
0.998 \\
0.998\end{array}$ & $\begin{array}{l}0.56 \% \\
0.51 \% \\
0.64 \%\end{array}$ \\
\hline Chen et al. [17] & 2012 & 40 & Healthy & $\begin{array}{l}\text { Sirius } \\
\text { Lenstar } 900 \\
\text { Sirius } \\
\text { Lenstar } 900 \\
\text { Sirius } \\
\text { Lenstar } 900\end{array}$ & $\begin{array}{l}\text { WTW } \\
\text { ACD } \\
\text { CCT }\end{array}$ & - & $\begin{array}{l}0.04 \mathrm{~mm} \\
0.05 \mathrm{~mm} \\
0.02 \mathrm{~mm} \\
0.02 \mathrm{~mm} \\
3.10 \mu \mathrm{m} \\
3.32 \mu \mathrm{m}\end{array}$ & - & - \\
\hline $\begin{array}{l}\text { Montalban } \\
\text { et al. [18] }\end{array}$ & 2012 & 117 & Healthy & Sirius & $\begin{array}{l}\text { WTW } \\
\text { ACD } \\
\text { CCT }\end{array}$ & - & $\begin{array}{l}0.06 \mathrm{~mm} \\
0.02 \mathrm{~mm} \\
2.80 \mu \mathrm{m}\end{array}$ & $\begin{array}{l}0.974 \\
0.999 \\
0.997\end{array}$ & $\begin{array}{l}0.48 \% \\
0.54 \% \\
0.52 \%\end{array}$ \\
\hline Nasser et al. [16] & 2012 & 45 & Healthy & Sirius & $A C D$ & - & - & - & $0.56 \%$ \\
\hline Savini et al. [19] & 2011 & 45 & Healthy & Galilei & $\begin{array}{l}\text { CCT } \\
\text { IA (4 quadrants) } \\
\text { WTW }\end{array}$ & - & - & $>0.94$ & $<3.5 \%$ \\
\hline
\end{tabular}

Abbreviations: $S D$ standard deviation, $S_{w}$ within-subject standard deviation, ICC intraclass correlation coefficient, CoV coefficient of variation, $D$ diopter

(Oculus) systems. Shin et al. [5] reported an ICC $>0.980$ for ACD measurements obtained with the Galilei G6 system in a sample of 140 eyes with cataract, and Savini et al. [19] obtained $\mathrm{CV}<3.5 \%$ and ICC $>0.94$ in 45 healthy eyes using the same system. With the Sirius system from CSO, Prakash et al. [6] obtained a mean value of $0.06 \mathrm{~mm}$ 
for $1.96 \mathrm{xS}_{\mathrm{w}}$ corresponding to $\mathrm{ACD}$ measurements in a sample of 100 healthy subjects. Likewise, Masoud et al. [10] obtained a $\mathrm{CV}<2 \%$ in 100 healthy eyes of 50 patients, Nasser et al. [16] a CV of $0.56 \%$ in 45 healthy eyes, and Montalbán et al. [18] $\mathrm{S}_{\mathrm{w}}, \mathrm{CV}$ and ICC of $0.02 \mathrm{~mm}, 0.54 \%$ and 0.999 in 117 healthy eyes, respectively. HernándezCamarena and coauthors [12] performed a comparative study of the repeatability of ACD measurements obtained with the Galilei G2 (Ziemer), Pentacam HR (Oculus) and Sirius (CSO) systems in 84 healthy eyes and found CV values below $1 \%$ in all cases. Shetty and coauthors [13] performed a similar comparison but in 55 keratoconus eyes and obtained $S_{\mathrm{w}}$ values of $0.03,0.05$ and $0.03 \mathrm{~mm}$ with the Pentacam, Galilei and Sirius systems, respectively. Therefore, the VX120 platform that uses Scheimpflug imaging for measuring ACD provides repeatable measurements of this anatomical parameter, with levels of reliability that are consistent with those found for other systems also based on Scheimpflug imaging or optical biometry (Table 4).

The intrasession repeatability of central and peripheral pachymetric readings obtained with the VX120 system in our sample was also excellent, with $S_{w}$ values below $9 \mu \mathrm{m}, \mathrm{CV}$ below $1.6 \%$ and ICC of more than 0.97 . Specifically, $S_{w}$ for central corneal thickness was $6.41 \mu \mathrm{m}$ in our sample, a value which is consistent with those reported using the Sirius system in healthy (Prakash et al. [6] $\mathrm{S}_{\mathrm{w}}: 5 \mu \mathrm{m}$; Montalbán et al. [18] $\mathrm{S}_{\mathrm{w}}$ : $2.80 \mu \mathrm{m}$; Chen et al. [17] $\left.\mathrm{S}_{\mathrm{w}}: 3.10 \mu \mathrm{m}\right)$ and keratoconus eyes (Montalbán et al. [14] $\mathrm{S}_{\mathrm{w}}: 2.30 \mu \mathrm{m}$ ). However, VX120 pachymetric repeatability outcomes were better than those reported for optical biometry systems (Zhao et al. [15] $\mathrm{S}_{\mathrm{w}}$ : 14.24 $\mu \mathrm{m}$, healthy eyes; Kunert et al. [4] $\mathrm{S}_{\mathrm{w}}: 19.5 \mu \mathrm{m}$ ) (Table 4). Concerning peripheral pachymetry, the readings obtained with the VX120 system were very repeatable, with $\mathrm{S}_{\mathrm{w}}$ values ranging from 5.91 to $8.98 \mu \mathrm{m}$. Milla and coauthors [20] evaluated the intrasession consistency of peripheral pachymetry obtained with the Scheimpflug imaging-based topography system Sirius from CSO and obtained $\mathrm{S}_{\mathrm{w}}$ values ranging from 3.1 to $5.8 \mu \mathrm{m}$. These values are consistent with those found in the current study. Likewise, other authors have reported similar $\mathrm{S}_{\mathrm{w}}$ or even worse than those obtained in the current series for minimal corneal thickness (Shetty et al. [13] $\mathrm{S}_{\mathrm{w}} 9.33 \mu \mathrm{m}$ Pentacam, $\mathrm{S}_{\mathrm{w}}$ $11.64 \mu \mathrm{m}$ Galilei, $S_{\mathrm{w}} 8.88 \mu \mathrm{m}$ Sirius, Montalbán et al. [14] $\mathrm{S}_{\mathrm{w}} 3.18 \mu \mathrm{m}$ ) (Table 4).

Besides ACD and pachymetry, the intrasession repeatability of WTW and iridocorneal angle measurements was also evaluated. In our series, excellent intrasession repeatability was found for WTW, with values of $0.24 \mathrm{~mm}, 1.95 \%$ and 0.873 for $\mathrm{S}_{\mathrm{w}}, \mathrm{CV}$ and ICC, respectively. Shajari and coauthors [3] reported in a sample of 40 healthy subjects in which WTW was measured with the Pentacam HR, IOL-Master 500, Lenstar 900 and Visante systems, a value of approximately $0.5 \mu \mathrm{m}$ for $1.96 \mathrm{xS}_{\mathrm{w}}$. Likewise, excellent intrasession repeatability for WTW has been also reported by other authors using a variety of devices: Galilei (Shin et al. [5] ICC $>0.980$ for cataract eyes; Savini et al. [19] ICC > 0.94 for healthy eyes), Lenstar 900 (Zhao et al. [15] Sw: $0.274 \mu \mathrm{m}$ for healthy eyes), Aladdin biometer (Huang et al. [8] ICC > 0.94 for healthy eyes, ICC: 0.795 for cataract eyes), Sirius (Montalbán et al. [14] $\mathrm{S}_{\mathrm{w}}$ : $0.07 \mathrm{~mm}$ for keratoconus eyes, Montalbán et al. [18] $\mathrm{S}_{\mathrm{w}}: 0.06 \mathrm{~mm}$ for healthy eyes), and IOL-Master system (Srivannaboon et al. [9] ICC $>0.93$ for cataract eyes). Concerning iridocorneal angle, an excellent intrasession repeatability was also obtained for nasal and temporal measurements over a horizontal scan, with $\mathrm{Sw}<0.9^{\circ}$, $\mathrm{CV}<2.3 \%$ and ICC $>0.97$. This level of repeatability is consistent with that reported for other Scheimpflug imaging-based topography systems [6, 10, 19]. Prakash et al. [6] reported values of $1.96 \mathrm{xS}_{\mathrm{w}}<2^{\circ}$ in iridocorneal angle measurements obtained with the Sirius system from CSO in a sample of 100 healthy subjects. Masoud et al. [10] found CV values below $2 \%$ for anterior chamber angle measurements obtained with the same topography system in another sample of 100 healthy eyes. Likewise, Savini et al. [19] found CV values below 3.5\% and ICC values of more than 0.94 for iridocorneal angle measurements in four quadrants obtained using the Galilei system in 45 healthy eyes. Therefore, the multidiagnostic platform VX120 is also able to provide repeatable measurements of WTW and iridocorneal angle, with levels of intrasession repeatability comparable to those reported for other commercially available systems (Table 4).

Finally, the level of correlation between the magnitude of all anatomical variables evaluated and their $S_{w}$ and $\mathrm{CV}$ values associated. Thus, we investigated if the level of repeatability of each anatomical parameter was dependent on its magnitude. This analysis revealed that this dependency was not present for any anatomical variable evaluated. Therefore, the VX120 system provides anatomical measurements of the anterior segment, with minimal repeatability errors that do not seem to increase in cases with extreme values within the normal range. More studies are needed to corroborate this finding in eyes with abnormal or pathological anterior segment, such as microcorneas and ectatic corneas.

The results of this study have only demonstrated that the VX120 system is able to provide repeatable measurements, which is crucial for being used as a diagnostic tool in clinical practice. However, future studies are necessary to evaluate the inter-observer repeatability and the interchangeability of the measurements provided by the VX120 platform with those obtained with other 
commercially available systems. In any case, good interobserver repeatability is expected to be found considering that measurements are taken automatically by the VX120 system, with minimal intervention from the observer. Indeed, the observer does not have to focus or center because this is done automatically by the system.

\section{Conclusion}

The multidiagnostic system VX120 seems to be able to provide consistent repeated measurements of ACD, central and peripheral pachymetry, WTW and iridocorneal angle in healthy eyes. The level of repeatability of the measurement of these anatomical parameters with the VX120 system is not dependent on the magnitude of such parameters, with the same precision ability for short and long eyes, small and large corneas, and eyes with deep and shallow anterior chamber within the normal range. Future studies should be conducted to confirm if this level of intrasession repeatability for the anatomical parameters evaluated is also observed in pathological eyes or after specific types of eye surgery. Furthermore, although measurements are done automatically by the device with minimal intervention of the operator, future inter-observer repeatability studies should be also performed.

\section{Abbreviations}

ACD: Anterior chamber depth; CCT: Central corneal thickness;

CDVA: Corrected distance visual acuity; CV: Coefficient of variation; IA: Iridocorneal angle; ICC: Intraclass correlation coefficient; IOP: Intraocular pressure; $\mathrm{PCT}$ : Peripheral corneal thickness; $\mathrm{PCT}_{\mathrm{N} 1}, \mathrm{PCT}_{\mathrm{N} 2}$, and $\mathrm{PCT}_{\mathrm{N} 3}$ : Peripheral corneal thickness at 1, 2 and $3 \mathrm{~mm}$ from vertex nasally; $P \mathrm{CT}_{T 1}, \mathrm{PCT}_{\mathrm{T} 2}$, and

$\mathrm{PCT}_{\mathrm{T3}}$ : Peripheral corneal thickness at 1,2 and $3 \mathrm{~mm}$ from vertex temporally; UDVA: Uncorrected distance visual acuity; WTW: White-to-white diameter

\section{Acknowledgements}

We acknowledge the Optometric Clinic of the University of Alicante for allowing us to develop this study in its facilities.

\section{Funding}

None

\section{Availability of data and materials}

The datasets during and/or analysed during the current study are available from the corresponding author on reasonable request.

\section{Authors' contributions}

Conception and design of the study: DPP, ALN, VJC. Acquisition of data: IC, ALN; DDF. Analysis and interpretation of data: DPP, IC, DDF, MTC. Drafting of the manuscript: DPP, IC. Critically revision of the manuscript: IC; ALN, DDF, MTC, VJC. All authors read and approved the final version to be published.

\section{Ethics approval and consent to participate}

An approval for the performance of the study was obtained from the Ethics Committee of the University of Alicante (Spain). All patients were informed previously about the study and signed an informed consent in accordance with the tenets of the Helsinki Declaration.

\section{Consent for publication}

Not applicable

\section{Competing interests}

The authors declare that they have no competing interests.

\section{Publisher's Note}

Springer Nature remains neutral with regard to jurisdictional claims in published maps and institutional affiliations.

\section{Author details}

${ }^{1}$ Group of Optics and Visual Perception, Department of Optics, Pharmacology and Anatomy, University of Alicante, Crta San Vicente del Raspeig s/n 03016, San Vicente del Raspeig, Alicante, Spain. ${ }^{2}$ Optometry Clinic, Prevention Service of the University of Alicante, Alicante, Spain.

Received: 3 October 2016 Accepted: 16 October 2017

Published online: 18 October 2017

\section{References}

1. Piñero DP. Technologies for anatomical and geometric characterization of the corneal structure and anterior segment: a review. Semin Ophthalmol. 2015;30:161-70.

2. Kurian M, Negalur N, Das S, Puttaiah NK, Haria D, TS J, Thakkar MM. Biometry with a new swept-source optical coherence tomography biometer: repeatability and agreement agreement with an optical lowcoherence reflectometry device. J Cataract Refract Surg. 2016;42:577-81.

3. Shajari M, Lehmann UC, Kohnen T. Comparison of corneal diameter and anterior chamber depth measurements using 4 different devices. Cornea. 2016:35:838-42

4. Kunert KS, Peter M, Blum M, Haigis W, Sekundo W, Schütze J, Büehren T. Repeatability and agreement in optical biometry of a new swept-source optical coherence tomography-based biometer versus partial coherence interferometry and optical low-coherence reflectometry. J Cataract Refract Surg. 2016:42:76-83.

5. Shin MC, Chung SY, Hwang HS, Han KE. Comparison of two optical biometers. Optom Vis Sci. 2016;93:259-65.

6. Prakash G, Srivastava D. Single session, intrauser repeatability of anterior chamber biometric and corneal pachy-volumetric parameters using a new Scheimpflug+Placido device. J Optom. 2016;9:85-92.

7. Cerviño A, Dominguez-Vicent A, Ferrer-Blasco T, García-Lázaro S, AlbarránDiego C. Intrasubject repeatability of corneal power, thickness, and wavefront aberrations with a new version of a dual rotating ScheimpflugPlacido system. J Cataract Refract Surg. 2015;41:186-92.

8. Huang J, Savini G, Wu F, Yu X, Yang J, Yu A, Yu Y, Wang Q. Repeatability and reproducibility of ocular biometry using a new noncontact optical lowcoherence interferometer. J Cataract Refract Surg. 2015:41:2233-41.

9. Srivannaboon S, Chirapapaisan C, Chonpimai P, Loket S. Clinical comparison of a new swept-source optical coherence tomography-based optical biometer and a time-domain optical coherence tomography-based optical biometer. J Cataract Refract Surg. 2015;41:2224-32.

10. Masoud M, Livny E, Bahar I. Repeatability and intrasession reproducibility obtained by the Sirius anterior segment analysis system. Eye Contact Lens. 2015:41:107-10.

11. Wang Q, Ding X, Savini G, Chen H, Feng Y, Pan C, Hua Y, Huang J. Anterior chamber depth measurements using Scheimpflug imaging and optical coherence tomography:repeatability, reproducibility, and agreement. J Cataract Refract Surg. 2015:41:178-85.

12. Hernández-Camarena JC, Chirinos-Saldaña P, Navas A, Ramirez-Miranda A, de la Mota A, Jimenez-Corona A, Graue-Hernindez EO. Repeatability, reproducibility, and agreement between three different Scheimpflug systems in measuring corneal and anterior segment biometry. J Refract Surg. 2014;30:616-21.

13. Shetty R, Arora V, Jayadev C, Nuijts RM, Kumar M, Puttaiah NK, Kummelil MK. Repeatability and agreement of three Scheimpflug-based imaging systems for measuring anterior segment parameters in keratoconus. Invest Ophthalmol Vis Sci. 2014;55:5263-8.

14. Montalbán R, Alió JL, Javaloy J, Piñero DP. Intrasubject repeatability in keratoconus-eye measurements obtained with a new Scheimpflug photography-based system. J Cataract Refract Surg. 2013;39:211-8.

15. Zhao J, Chen Z, Zhou Z, Ding L, Zhou X. Evaluation of the repeatability of the Lenstar and comparison with two other non-contact biometric devices in myopes. Clin Exp Optom. 2013:96:92-9.

16. Nasser CK, Singer R, Barkana Y, Zadok D, Avni I, Goldich Y. Repeatability of the Sirius imaging system and agreement with the Pentacam HR. J Refract Surg. 2012;28:493-7. 
17. Chen W, McAlinden C, Pesudovs K, Wang Q, Lu F, Feng Y, Chen J, Huang J. Scheimpflug-Placido topographer and optical low-coherence reflectometry biometer: repeatability and agreement. J Cataract Refract Surg. 2012;38:1626-32.

18. Montalbán R, Piñero DP, Javaloy J, Alió JL. Intrasubject repeatability of corneal morphology measurements obtained with a new Scheimpflug photography-based system. J Cataract Refract Surg. 2012;38:971-7.

19. Savini G, Carbonelli M, Barboni P, Hoffer KJ. Repeatability of automatic measurements performed by a dual Scheimpflug analyzer in unoperated and post-refractive surgery eyes. J Cataract Refract Surg. 2011;37:302-9.

20. Milla M, Piñero DP, Amparo F, Alió JL. Pachymetric measurements with a new Scheimpflug photography-based system. Intraobserver repeatability and agreement with optical coherence tomography pachymetry. J Cataract Refract Surg. 2011;37:310-6.

21. Asgari S, Hashemi H, Jafarzadehpur E, Mohamadi A, Rezvan F, Fotouhi A. OPD-Scan III: a repeatability and inter-device agreement study of a multifunctional device in emmetropia, ametropia, and keratoconus. Int Ophthalmol. 2016; [Epub ahead of print]

22. Piñero DP, Juan JT, Alió JL. Intrasubject repeatability of internal aberrometry obtained with a new integrated aberrometer. J Refract Surg. 2011;27:509-17.

23. López-Miquel A, Martínez-Almeida L, González-García MJ, Coco-Martín MB, Sobrado-Calvo P, Maldonado MJ. Precision of higher-order aberration measurements with a new Placido-disk topographer and Hartmann-Shack wavefront sensor. J Cataract Refract Surg. 2013;39:242-9.

\section{Submit your next manuscript to BioMed Central and we will help you at every step:}

- We accept pre-submission inquiries

- Our selector tool helps you to find the most relevant journal

- We provide round the clock customer support

- Convenient online submission

- Thorough peer review

- Inclusion in PubMed and all major indexing services

- Maximum visibility for your research

Submit your manuscript at www.biomedcentral.com/submit

) Biomed Central 